\title{
Regularities of Regulations on Impacting Irrigated Water Land
}

\author{
Lola Karshiboeva , Gulistan State University Republic of Uzbekistan \\ Juraev Adham, Gulistan State University Republic of Uzbekistan \\ Sattarov Sobidkhon, Gulistan State University Republic of Uzbekistan \\ Ishankulova Komila , Gulistan State University Republic of Uzbekistan \\ Zulfiya Madrahimova, Gulistan State University Republic of Uzbekistan \\ Mukhayo Altiboeva, Gulistan State University Republic of Uzbekistan \\ Rano Kurolova, Gulistan State University Republic of Uzbekistan
}

\begin{abstract}
Regularities of norms on water absorption of irrigated lands" Considered the costs of filtration, through which the rate of water absorption by irrigated lands is estimated. Filtration estimates are considered through the difference between the distribution of velocities of clean and turbid water. To determine the regularity of the distribution of velocities over the depth of the pure flow, we will use the equation of motion.
\end{abstract}

Keywords: Considered, Irrigation nutrition, Influence of irrigation, Results, filtration, land, distribution patterns, self-cleaning.

Received: 07.12.2020 Accepted: 12.01 .2021

Published: 06.02.2021

\section{INTRODUCTION}

The main purpose of environmental education is to form in students a conscious attitude to the environment and its problems, as well as the knowledge, skills and abilities to find optimal solutions to them. In order to achieve this goal, we have to solve a number of tasks to save their place (nature) and riches teaching conscious conservation. Formation of ecological culture. It should start, first of all, with the family. This is stated in the first paragraph of this chapter. In the formation of ecological culture among students, special attention should be paid to the following aspects: the fact that environmental pollution is a source of disease for humans, the consequences of fires on the environment and fire prevention.

to teach to take measures. Formation of ecological literacy. It is better to use real-life examples in educating students about the consequences of the destruction of grass on vacation and the impact of broken glass on society, nature and human health. to inculcate in students the harmful effects of intolerance on trees, plants and animals, the impact of harmful emissions from factories and plants on human development and its consequences. Achieving the creation of information and communication technologies, environmental education in the teaching of all disciplines in the training of future professionals, environmental education in extracurricular activities and excursions and trips, teaching students about environmental issues in the teaching of science protection, o to form the knowledge, skills and competencies that are given priority in the rational use of the resources of, to provide students with knowledge about the concepts and laws of ecology. It focuses on the concepts and laws of labor protection, nature conservation, the list of rare species, the prevention of crises in nature and the atmosphere. So, one of the goals of environmental education of students - on the one hand - to clean our sacred Motherland. on the other hand, it is to keep our clear sky as it really is. This is a great contribution to the prosperity of our homeland, with the help of which human qualities such as well-being and modesty, cleanliness and thrift, kindness and gentleness are formed in students. These ensure that students have a conscious understanding of the following environmental laws and concepts:When irrigating agricultural fields, part of the water is used to feed the plants, part of it evaporates, and part (not counting the discharged from the fields) is spent on feeding groundwater. In this regard, the level of groundwater rises, as a result of which their evaporation and accumulation of salts in the zone of aeration and groundwater become more active. As a result, soil salinization may occur, which causes a decrease in the yield of agricultural crops. Additional feeding of groundwater also occurs when water is filtered from main, distribution and irrigation canals. All these processes lead to a change in the groundwater regime not only on irrigated, but also on non-irrigated areas located within the irrigated massifs. The main hydrological indicators that transform landscapes in the irrigated zone are the volume of water supply 
(irrigation rate) and the amount of irrigation recharge. The irrigation rate is the volume of water that ensures the maintenance of moisture in the root layer of the soil, optimal for the growth and development of plants and the formation of the maximum crop yield. Optimal bioclimatic irrigation rates net $(\mathrm{mm})$ of agricultural crops in various natural and climatic zones Russia, with different levels of groundwater occurrence and for different moisture availability for the year are given in the reference book on land reclamation and water management (irrigation).

\section{Irrigation groundwater supply.}

Irrigation recharge of groundwater (including infiltration recharge during irrigation and filtration losses from irrigation canals) is the main hydrodynamic indicator that needs to be limited. When assessing infiltration nutrition during irrigation and the beginning of the process of raising the level of groundwater, it is necessary to take into account the possibility of transit flows of irrigation water through the root layer in volumes reaching, as a rule, about $20 \%$ of the total losses of water for filtration. Filtration losses from the irrigation network (from main canals, inter-farm and on-farm networks) can reach $40-50 \%$ of the canal discharge. For various landscape and climatic zones (depending on the total water consumption of agricultural crops), environmental restrictions on the amount of infiltration supply are proposed groundwater, filtration losses from canals and irrigation network and by the total irrigation supply of groundwater at the existing technical and technological level of development of irrigation reclamation. The role of irrigation water filtered through the bottom and walls of canals, depending on natural conditions can be different. Penetrating into aquifers and being less dense, they float on the surface of the underlying weakly and strongly brackish waters, forming a kind of lenses and replenishing the reserves of groundwater. In conditions of good outflow, they wash the soil and rocks from salts. In the case of low filtration properties of rocks and in the absence of outflow in some areas, the groundwater level rises and flooding, while in others, due to evaporation, soil salinization develops. The problem of soil utilization of waste for fertilizers has diverse aspects and is inseparable from the problem of soil fertility and ecology ... Many years of experience in the use of livestock wastewater for irrigation of forage crops has shown their high efficiency - the yield of plants increases 2-3 times or more in comparison with rainfed crops. The results of scientific research have shown that irrigation of perennial grasses with livestock drains increases soil fertility (the humus content increases, the degree of saturation with bases increases, the amount of potassium and phosphorus increases, the content of manganese and copper increases). Irrigation with livestock effluents while optimizing irrigation rates also increases the quality of perennial grasses - the content of crude protein, the total amount of amino acids, the content of potassium, phosphorus increases. Summer grasses, especially cereals, as a source of roughage, hay, haylage, silage, grass meal. On lands irrigated with waste water, crops should be grown that are characterized by a positive reaction to non-vegetation irrigation with year-round regular and cyclic irrigation. Irrigation with waste and saline waters in a number of cases has a significant effect on the groundwater regime. This type of irrigation presupposes, on the one hand, self-purification of wastewater, and on the other hand, the use of agricultural crops of nutrients contained in these waters. Wastewater irrigation usually results in groundwater contamination and a rise in its level. So, in a number of areas of irrigation fields in the Donbass over 25 years, the groundwater level has risen, salinity has increased from 0.5 to $2.8 \mathrm{~g} / \mathrm{l}$, the hydrocarbonate composition of groundwater has changed to a sulfate composition.

If the groundwater from above is blocked by dense water-impermeable rocks, then there may be no pollution. So, in areas near Lyubertsy and with. Kudinovo, despite the 80-year period of irrigation with wastewater, groundwater pollution has not been established. To use waste water as irrigation water, a detailed study of the hydrogeological conditions of the area, in particular the natural regime and elements of the groundwater balance, is necessary.

The influence of irrigation on groundwater and soil cover is intensely manifested in areas of low natural drainage. This effect is all the more negative, the lower the efficiency of irrigation systems, the greater the amount of water supply for irrigation and the lower the intensity of artificial drainage. The noted negative aspects of irrigation and reclamation are to a large extent inherent in the regions of Central Asia with low natural drainage, mainly related to the irrigated lands of the Syrdarya and Amudarya river basins. These areas are one of the most ancient regions of irrigated agriculture and currently have great opportunities for the development of fallow lands. [3] Filtration costs are considered in many problems. Knowing the cost of filtration, it is possible to estimate the rate of water absorption by irrigated lands. 
For this problem, to assess the filtration rate, consider the difference between the distribution of velocities of pure and turbid water. To determine the regularity of the distribution of velocities along the depth of the pure flow, we take the following equations of motion as the initial ones:

(1) $\frac{\partial u}{\partial t}+\sum_{i=1}^{n} u_{i} \frac{\partial u_{j}}{\partial x_{i}}=F_{i}-\frac{1}{\rho} \frac{\partial p}{\partial x_{i}}+\sum_{i=1}^{n} \frac{\partial}{\partial x_{i}} \frac{1}{\rho} A \frac{\partial u_{j}}{\partial x_{i}}$

and non-discontinuity of the following form

$$
\sum_{i=1}^{n} \frac{\partial u_{j}}{\partial x_{i}}=0
$$

Where: $i=1,2,3 j=1,2,3 ; n=3, u_{i}$ - components of the velocity vector; $t$ - time; $F_{i}$ - components of external forces; $g$-acceleration of gravity; $\rho$-water density; $\quad \rho$-pressure; $A$-coefficient of turbulent exchange; $x_{i}$ - coordinates of a rectangular system; the coordinates are arranged as follows: $x_{1}=x$ downstream; $x_{2}=y$ - in depth from surface to bottom; $x_{3}=z$-across the stream; $F_{i}$ - acting external gravity:

$$
F_{1}=g i_{0} ; \quad F_{2}=-g^{\prime}, \quad F_{3}=0
$$

Consider the formula for one-dimensional steady motion,

$$
\begin{aligned}
& \frac{\partial u_{x}}{\partial t}=\frac{\partial u_{y}}{\partial t}=\frac{\partial u_{z}}{\partial t}=0 \\
& u_{y}=u_{z}=0
\end{aligned}
$$

Under these assumptions, equations (1) and (2) take the form [1,2]:

$$
\begin{gathered}
u_{x} \frac{\partial u_{x}}{\partial x}=g i_{0}-\frac{1}{\rho} \frac{\partial p}{\partial x}+\frac{1}{\rho} \frac{\partial}{\partial x} A \frac{\partial u_{x}}{\partial x}+\frac{1}{\rho} \frac{\partial}{\partial y} A \frac{\partial u_{x}}{\partial y} \\
\frac{\partial p}{\partial y}=\rho g \frac{\partial p}{\partial z}=0 \\
\frac{\partial u_{x}}{\partial x}=0
\end{gathered}
$$

From dependencies (4) it follows that

(6)

$$
\frac{\partial p}{\partial x}=0
$$

Substituting equalities (5) and (6) into formula (3), we get:

$$
\frac{1}{\rho} \frac{\partial}{\partial y} A \frac{\partial u_{x}}{\partial y}+g i_{0}=0
$$

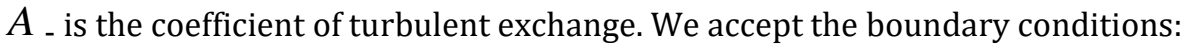

Consequently, the problem is reduced to solving equation (7)

$$
\left.\begin{array}{l}
u_{x}=u_{0} \ldots n p u \ldots y=0 \\
u_{x}=u_{\text {д } . . n p u . . . y=H}
\end{array}\right\}
$$

in the boundary conditions (8).

The coefficient of turbulent exchange is of great importance in solving a wide variety of theoretical and practical problems. To determine the coefficient of turbulent exchange - $A$, with a vertical axis of distribution 
of velocities, using the logarithmic equation or a parabola with a vertical axis to express the velocity profile, we find a very peculiar distribution curve. For zero or close to zero values at the walls - $A$, maximum in the middle and zero values on the pipe axis, we find by the approach of A.V. Karaushev. Which received a smooth increase in the coefficient of turbulent exchange from the bottom to the surface of the flow. The coefficient of turbulent exchange can be approximated as follows:

$$
A(y)=\frac{A_{c p}}{\sum_{i=0}^{n} a_{i} y^{i}}
$$

Where $a_{i}$-are the coefficients to be determined; $A_{c p}$ - the average value of the coefficient of turbulent exchange:

$$
A_{c p}=\frac{\rho g H u_{c p}}{2 m C}
$$

Here is the flow depth; $H-$ average vertical speed; $u_{c p}$ - for. ; $m=0,35 C+310 \leq C \leq 60$.C - is the Shezy coefficient. Substituting formula (10) into equation (9), we get:

$$
A(y)=\frac{\rho g H u_{c p}}{2 m C}=\frac{1}{a_{0}+a_{1} y+a_{2} y^{2}+}
$$

First, consider a simpler case, that is, assume that, then: $a_{0} \neq 0, a_{1}=a_{2}=\ldots=a_{n}=0$

$$
A(y)=\frac{\rho g H u_{c p}}{2 m C a_{0}}
$$

After substitution of the obtained expression in the formula (7):

$$
\frac{d}{d y}\left(\frac{\rho g H u_{c p}}{2 m C a_{0}} \frac{d u_{x}}{d y}\right)=-\rho g i_{0}
$$

or

$$
\frac{\rho g H u_{c p}}{2 m C a_{0}} \frac{d^{2} u_{x}}{d y^{2}}=-\rho g i_{0}
$$

Whence follows:

$$
\frac{d^{2} u_{x}}{d y^{2}}=-\frac{2 m C a_{0} i_{0}}{H u_{c p}}
$$

After double integration

$$
u_{x}=-\frac{2 m C a_{0} i_{0}}{H u_{c p}} y^{2}+C_{1} y+C_{2}
$$

From the boundary conditions (8) we find:

$$
C_{1}=\frac{m u_{*} C a_{0}}{\sqrt{g}}-\left(u_{0}-u_{\text {Д }}\right) ; u_{0}=C_{2}
$$

Where $u_{*}=\sqrt{g H i_{0}}$ - is the dynamic speed.

Substituting the values $C_{1}$ and $C_{2}$ into formula (12), we find the velocity distribution:

$$
u_{x}=u_{0}+\left[\left(\frac{m u_{*} a_{0}}{\sqrt{g}}\right)-\left(u_{0}-u_{\text {Д }}\right)\right] \eta-\left(\frac{m u_{*} a_{0}}{\sqrt{g}}\right) \eta^{2}
$$


Where $\eta=\frac{y}{H}$ - is the relative depth. Formula (13) is a three-term parabola. The three-term form of the parabola for the velocity distribution was proposed by I.I.Agroskin and G.T.Dmitriev in the form

$$
u_{x}=u_{0}+2 m_{1} N \eta-N \eta^{2}
$$

Comparing expression (12) with formula (13), we get:

$$
N=\left(\frac{m u_{*} a_{0}}{\sqrt{g}}\right) m_{1}=N+u_{\text {д }}+\frac{u_{0}}{2 N}
$$

Now we will solve equation

$$
A(y)=\frac{\rho g H u_{c p}}{2 m C}=\frac{1}{a_{0}+a_{1} y}
$$

(11) in the first approximation, i.e.

After substituting expression (16) into formula (7) and simple transformations, we find:

After integration

$$
\frac{d u_{x}}{d y}=-\frac{2 m C a_{0} i_{0}}{H u_{c p}} y\left(a_{0}+a_{1} y\right)+C_{3}\left(a_{0}+a_{1} y\right) \quad u_{x}=-\frac{2 m C a_{0} i_{0}}{H u_{c p}}\left(a_{0} \frac{y^{2}}{2}+a_{1} \frac{y^{2}}{3}\right)^{2}+C_{3}\left(a_{0} y+a_{1} \frac{y}{2}\right.
$$

$$
\begin{array}{ll}
\text { From } & \text { the } \\
C_{3}=\frac{1}{a_{0}+\frac{a_{1} H}{2}}\left[\frac{2 m u_{*}}{H \sqrt{g}}\left(\frac{a_{0}}{2}+\frac{a_{1} H}{3}\right)-\frac{\left(_{0}-u_{д}\right)}{H}\right] C_{4}=u_{0}
\end{array}
$$

Substituting the values of $\mathrm{C}_{3}$ and $\mathrm{C}_{4}$ into formula (16), for the first approximation we find:

$$
u_{x}=u_{0}+\frac{\left(\frac{2 m u_{*}}{\sqrt{g}}\right)\left(\frac{a_{0}}{2}+\frac{a_{1} H}{3}\right)-\left(u_{0}-u_{\text {д }}\right)}{a_{0}+\frac{a_{1} H}{2}}\left(a_{0}+\frac{a_{1} H}{2} \eta\right) \eta-\frac{2 m u_{*}}{\sqrt{g}}\left(\frac{a_{0}}{2}+a_{1} \frac{H}{3} \eta\right) \eta^{2}
$$

At, expression (13) is obtained from formula $a_{1}=0$ (17). Solving equation (11) in the same way for the second approximation, we get:

$$
\begin{aligned}
& u_{x}=u_{0}+\frac{\left(\frac{2 m u_{*}}{\sqrt{g}}\right)\left(\frac{a_{0}}{2}+\frac{a_{1} H}{3}+\frac{a_{2} H^{2}}{4}\right)-\left(u_{0}-u_{\text {д }}\right)}{a_{0}+\frac{a_{1} H}{2}+\frac{a_{2} H^{2}}{3}}\left(a_{0}+\frac{a_{1} H \eta}{2}+\frac{a_{2} H^{2} \eta^{2}}{2}\right) \eta- \\
& -\frac{2 m u_{*}}{\sqrt{g}}\left(\frac{a_{0}}{2}+a_{1} \frac{H}{3} \eta+a_{2} \frac{H^{2}}{4} \eta^{2}\right) \eta^{2}
\end{aligned}
$$

From formula (18) is obtained at $a_{1}=a_{2}=0$ zero and at the first $a_{2}=0$ approximation of the equation. Suppose that, $a_{0}=a_{1}=a_{2}=1$ then 


$$
\begin{aligned}
& u_{x}=u_{0}+\frac{\left(\frac{2 m u_{*}}{\sqrt{g}}\right)\left(\frac{1}{2}+\frac{H}{3}+\frac{H^{2}}{4}\right)-\left(u_{0}-u_{\text {Д }}\right)}{a_{0}+\frac{H}{2}+\frac{H^{2}}{3}}\left(1+\frac{H \eta}{2}+\frac{H^{2} \eta^{2}}{2}\right) \eta- \\
& -\frac{2 m u_{*}}{\sqrt{g}}\left(\frac{1}{2}+\frac{H}{3} \eta+\frac{H^{2}}{4} \eta^{2}\right) \eta^{2}
\end{aligned}
$$

The bottom velocity included $u_{д}$, in formulas (18) and (19) is determined from the expression

$$
\begin{aligned}
& u_{c p}=\int_{0}^{1} u_{x} d \eta \\
& u_{\text {म }}=\frac{B_{2}}{B_{3}} u_{c p}+\frac{B_{2}-B_{3}}{B_{3}} u_{0}-\frac{2 m u_{*}}{3 \sqrt{g}} \frac{B_{1} B_{3}-B_{2} B_{4}}{B_{3}}
\end{aligned}
$$

Where

$$
\begin{aligned}
B_{1}=\frac{a_{0}}{2}+\frac{a_{1} H}{3} & +\frac{a_{2} H^{2}}{4} \\
B_{2} & =a_{0}+\frac{a_{1} H}{2}+\frac{a_{2} H^{2}}{3} \\
B_{3} & =\frac{a_{0}}{2}+\frac{a_{1} H}{6}+\frac{a_{2}}{12} \\
B_{4} & =\frac{a_{0}}{6}+\frac{a_{1} H}{12}+\frac{a_{2} H^{2}}{20}
\end{aligned}
$$

For $a_{1}=a_{2}=0$ и $a_{0}=1$ and we obtain the formula for the velocity distribution:

$$
u_{x}=u_{0}+\left[\left(\frac{m u_{*} a_{0}}{\sqrt{g}}\right)-\left(u_{0}-u_{\text {д }}\right)\right] \eta-\left(\frac{m u_{*} a_{0}}{\sqrt{g}}\right) \eta^{2}
$$

for bottom speed - the formula

$$
u_{\text {д }}=2 u_{c p}-u_{0}-\frac{2 m u_{*}}{3 \sqrt{g}}
$$

Thus, in a more general case, the vertical velocity distribution is determined by formula (19), from which, as a special case, simplified formulas can be obtained.

To find the costs, we obtain the product of the distribution of speeds by the transverse area.

\section{REFERENCES}

1. Ibad-zade Yu.A., Azizov SG Regularities of the distribution of velocities and turbidity along the vertical in a two-phase open flow. - For technical progress, 1972, No. 10, pp. 37-39.

2. Karasev I.F. Channel processes during flow transfer. L., 1975, 288

3. Natishvili 0.G. On the transport of suspended solids by a turbulent channel flow. - Tr. in-that. GruzNIIGiM, 1965, no. 23, p. 56-59.

4. Melioration: stages and development prospects. Materials of the international scientific and industrial conference. - M., 2006. State Scientific Institution All-Russian Scientific Research Institute of Hydraulic Engineering and Land Reclamation named after A. N. Kostyakov.

5. Ministry of Agriculture of the Russian Federation Federal State Scientific Institution "RUSSIAN SCIENTIFIC RESEARCH INSTITUTE OF RECLAMATION PROBLEMS" (FGNU "RosNIIPM") Novocherkassk 2010.

6. AGRICULTURAL HYDROTECHNICAL RECLAMATIONS. Tashkent Institute of Irrigation and Melioration, 2007 
7. Guidelines for the management of saline soils Edited by R. Vargas, E.I. Pankova, S.A. Balyuk, P.V. Krasilnikov and G.M. Khasankhanova, FOOD AND AGRICULTURE ORGANIZATION OF THE UNITED NATIONS Rome, 2017 8. WAYS OF INCREASING THE EFFICIENCY OF IRRIGATED AGRICULTURE Collection of scientific papers. FGBNU "RosNIIPM", 2014.

9. Water supply. General Provisions. SNB 4.01.01-03.

10. Hydrological calculations in the design of drainage and drainage and humidification systems / Shebeko V.F., Zakrzhevsky PI, Bragilevskaya E.A. - L .: Gidrometeoizdat, 1980. 
